\title{
Clinical factors correlated with the success rate of miniscrews in orthodontic treatment
}

\author{
Nikolaos Topouzelis and Phoebus Tsaousoglou
}

Miniscrews offer a reliable alternative for anchorage during orthodontic treatment, particularly for non-cooperative patients or periodontal patients with alveolar bone loss. The study aims at assessing the correlation of various clinical indicators with the success or failure of miniscrews used for anchorage during orthodontic treatment. Thirty-four consecutive patients with a cumulative total of 82 miniscrews implanted participated in the study. Generalized Estimating Equations were used to assess the correlation of various factors with success rates. The miniscrew was considered the unit of analysis clustered within site and within patient. The overall success rate of miniscrews was $90.2 \%$. For every additional miniscrew used in a patient's oral cavity, the success rate was reduced by $67 \%$. Retromandibular triangle and palatal placement and in movable mucosa resulted in lower success rate. The miniscrew length and diameter were found to correlate with success rates. Orthodontic force applied on miniscrews for uprighting purposes showed a lower success rate than that used for retraction. This study revealed that miniscrews present high success rates. The number of miniscrews used per patient, the miniscrew site placement, the soft tissue type of placement, the miniscrew length and diameter as well as the orthodontic force applied on the miniscrew showed significant correlation with success rates.

International Journal of Oral Science (2012) 4, 38-44; doi:10.1038/ijos.2012.1; published online 12 January 2012

Keywords: miniscrews; orthodontic anchorage; success rate

\section{INTRODUCTION}

Ensuring proper anchorage is a major concern when orthodontic forces are applied. On the basis of Newton's third law, for every action there is an equal and opposite reaction, the impact of which is often undesirable during orthodontic treatment. In their efforts to eliminate or restrict such undesirable parameters, orthodontists have used conventional intra-oral and extra-oral anchorage, such as headgear and other orthodontic devices. However, this often means reduced compliance among young patients due to aesthetics and other social factors. Along with the increased use of osseo-integrated implants in orthodontics, there has been an increase in the application of smaller implants. The use of the former and their success rates are fully documented with excellent long-term success rates. ${ }^{1-5}$ Higuchi and Slack ${ }^{6}$ used 14 osseo-integrated implants in seven patients for orthodontic teeth movement. In the above and another study, implants remained stable throughout the treatment and procedures yielded good results. ${ }^{6-7}$ In spite of their successful use, osseo-integrated implant size and additional cost as well as the need for two extensive surgical procedures have limited their use in orthodontics. In recent years, implant anchorage systems have been developed and used successfully as an alternative to a headgear. ${ }^{8-12}$

Different terms have been used for mini-implants in the literature, such as: Miniscrews, Miniscrew implants, Microscrews and Temporary anchorage devices. ${ }^{13}$ The term used in this paper is 'miniscrew'. A number of studies have made reference to the use of miniscrews. However, the success rates reported vary widely and there is a wide range of possible risk factors that should be taken into account.

Miniscrews are an alternative to osseo-integrated implants; they can be inserted and removed easily, are more affordable and can be inserted at various maxillary and mandibular sites. Miniscrews can even be inserted between teeth roots due to their small size, which also makes them more comfortable for patients. Kanomi ${ }^{12}$ has described the successful use of miniscrews ( $6 \mathrm{~mm}$ long, $1.2 \mathrm{~mm}$ in diameter) so as to intrude lower molars by $6 \mathrm{~mm}$ without any root absorption or periodontal problems. It should be noted that miniscrews can only be used for a limited period of time; they are not osseo integrated like conventional implants, but they do rely on mechanical retention in the bone.

Nowadays, miniscrews are widely available for orthodontic reinforcement. Orthodontists have been using miniscrews more frequently in their daily clinical practice and are seeking clear, evidence-based information about their success rates and risk indicators affecting successful outcomes. Consequently, there is worldwide interest in miniscrew stability and the success rates of procedures using miniscrews; this is why researchers are also focusing on factors affecting the success or failure of miniscrews. A recent systematic review concludes that research to date does not allow conclusions to be drawn in terms of the success or failure rates of any particular type of miniscrew (length or diameter) or of other factors, such as the technique or site of placement, type of loading, and so on. ${ }^{14}$ There are numerous papers available in the relevant literature investigating the success or 
failure of miniscrews. A unanimous conclusion is that the usage of miniscrews presents high success rate. However, there is no consensus as to the risk and indicator factors and the extent to which possible factors impact such success or failure. Besides, studies that take into account a lot of factors together are not enough and this is important, considering that the success rate of a miniscrew is a multifactorial origin.

The purpose of this retrospective study is to assess the success rate of miniscrews and to correlate indicators which may be affecting their success, namely, the indicators that may have an impact on the stability of miniscrews during the time period required for orthodontic treatment.

\section{MATERIALS AND METHODS}

Thirty-four patients were included in this study and a total of 82 miniscrews (Dual-Top Anchor System; Jeil Medical Corporation, Seoul, Korea) were used for skeletal anchorage during orthodontic treatment from September 2006 to December 2009 at the author's private practice (TN). Patients included 21 female and 13 male patients, aged from 15 to 45 years (mean age: $27.2 \pm 7.3$ years). The numbers of patients ( 21 female and 13 male) with and without a history of smoking were 10 and 24 respectively. Patients or their parents were informed about the procedure prior to surgery, written consent was obtained and the same protocol was followed in all cases for the surgical placement of the miniscrews.

Titanium miniscrews were inserted using a self-drilling procedure under local anesthesia. Oral cavities were rinsed with chlorhexidine digluconate $(0.12 \%)$. A manual screwdriver was then used to penetrate the soft tissue and the cortical bone under irrigation with physiological saline $(0.9 \%)$ in order to insert the miniscrews. When necessary, an incision was made and a minor flap rose to allow placement of the miniscrew. The application of orthodontic force started 2 weeks after implantation. A force of $0.98-1.96 \mathrm{~N}$ was loaded onto an elastomeric chain or a closed-type NiTi coil spring. When the implantation site lay on the palatal side, a longer miniscrew $(10 \mathrm{~mm})$ was used to compensate for the thickness of the palatal mucosa. Following surgery, patients were instructed to maintain meticulous oral hygiene of the soft tissue around the transmucosal portion of the miniscrews and to keep teeth free of inflammation by using a soft toothbrush and a chlorhexidine oral rinse $(0.12 \%)$ for 2 weeks. No antibiotics or painkillers were prescribed.

In order to determine the exact location for miniscrew placement, periapical radiographs (paralleling technique) and surgical matrix models were used. The surgical matrix models were fabricated from orthodontic wire and silicone impressing material so as to avoid damaging the roots of adjacent teeth or adjacent anatomical structures.

A miniscrew was considered successful when there was no inflammation or clinically detectable mobility present nor any dental root or other anatomical structure damage, and when the miniscrew was stable for the time period necessary to conclude the orthodontic treatment undertaken. Conversely, a miniscrew was considered to have failed when there was an infection that did not resolve with conservative treatment, or dislodgement or remarkable mobility that could not sustain orthodontic force. The miniscrew loading time was measured from the moment of each miniscrew placement to the point when there was no need for applying orthodontic forces any more or to the point of failure.

The following factors were examined: gender, patient age, smoking, number of miniscrews per patient, miniscrew diameter, miniscrew length, type of malocclusion (Angle Class I or II/1), dentoalveolar abnormality (open bite or crowding), site of miniscrew placement (buccal, palatal), jaw of miniscrew placement (maxilla or mandible), surgical placement procedure (flapped or flapless), type of soft tissue within which the miniscrew was placed (attached gingiva or movable mucosa), orthodontic force applied on miniscrews for retraction, protraction, intrusion or uprighting.

\section{Statistical analysis}

Miniscrews were placed at 15 different sites (Table 1) and one to five miniscrews were inserted in each patient. Therefore, the correlation between any risk indicator and the dependent binary variable (success-failure) was based on a Logistic Regression model for clustered data, considering, hierarchically, miniscrew within site and within patient. Accordingly, for each of the independent variables, a Generalized Estimating Equation model with logit as the link function was fitted. The strength of the association between factors and outcome was derived through the odds ratio (OR) statistic with a corresponding 95\% confidence interval. As expected from the results of previous studies, the significant difference between the number of successes and failures did not allow simultaneous examination of all factors using a single statistical model. Consequently, a comparison between statistically significant factors was performed using the Bonferroni method. For the 12 parameters assessed here, a $P$ value lower than $0.0042(0.05 / 12)$ was considered statistically significant. The analysis was performed using the SPSS 16.0 software (version 16; SPSS, Chicago, IL, USA). The level of statistical significance for all tests was set at $P<0.05 .^{15-16}$

\section{RESULTS}

Eighty-two miniscrews were applied at 15 different anatomical locations (Table 1). The overall success rate of miniscrews was $90.2 \%$ $(\mathrm{OR}=9.3,95 \% \mathrm{CI}: 5.4-16)$ and only eight failures were noted. The earliest failure occurred in the first month after placement and the latest in the fourth month after placement. Mean loading time for all miniscrews was 8 months, ranging from 1 to 14 months. Mean loading time for failed miniscrews was 2.5 months, ranging from 1 to 4 months. It was, therefore, observed that all miniscrew losses occurred in the first 4 months (Table 2).

Table 1 Fifteen placement site of miniscrew correlated with results

\begin{tabular}{lccc}
\hline & \multicolumn{3}{l}{ Result } \\
\cline { 2 - 4 } Placement site & Success $(n)^{*}$ & Failure $(n)^{*}$ & Total \\
\hline $15-16$ buccal & 23 & 0 & 23 \\
$25-26$ buccal & 25 & 1 & 26 \\
$35-36$ buccal & 6 & 0 & 6 \\
$45-46$ buccal & 4 & 1 & 5 \\
$26-27$ buccal & 1 & 0 & 1 \\
$43-44$ buccal & 2 & 1 & 3 \\
$26-27$ palatal & 3 & 1 & 4 \\
$16-17$ palatal & 3 & 1 & 4 \\
37 retromandibular triangle & 2 & 0 & 2 \\
47 retromandibular triangle & 1 & 2 & 3 \\
47 mesial & 1 & 0 & 1 \\
16 buccal-distal & 1 & 0 & 1 \\
26 buccal-distal & 1 & 0 & 1 \\
16 palatal-mesial & 1 & 0 & 1 \\
26 palatal-mesial & 0 & 1 & 1 \\
Total & 74 & 8 & 82 \\
\hline
\end{tabular}

$*(n)$, number of miniscrews. 
Table 2 Mean loading time of miniscrews

\begin{tabular}{ll}
\hline Categories of loading time & Time \\
\hline Mean loading time (range) & $8(1-14)$ \\
Mean loading time with success (range) & $9.5(6-14)$ \\
Mean loading time with failure (range) & $2.5(1-4)$ \\
\hline
\end{tabular}

The number of miniscrews per patient, the site of placement (retromandibular triangle, palatal, buccal), the type of soft tissue within which the miniscrew was placed (attached gingiva or movable mucosa), the miniscrew length and diameter, the surgical placement procedure (flapped or flapless) used and the orthodontic force applied on the miniscrew, all showed significant correlation with success rates. Details of the miniscrews implanted are summarized in Table 3.

Table 3 Description of the data and estimated odds ratio from the Generalized Estimating Equations models (referral category 'Failure')

\begin{tabular}{|c|c|c|c|c|}
\hline Factor/variable & Success & Failure & OR $(95 \% \mathrm{Cl})$ & $P$ value \\
\hline Total miniscrews & $74(90.2 \%)$ & $8(9.8 \%)$ & $9.3(5.4-16)$ & $<0.001^{* * *}$ \\
\hline Age (mean ${ }^{a} \pm$ s.d.) (range) & $29 \pm 8.3(15-45)$ & $26.7 \pm 4.1(22-32)$ & $1.05(0.98-1.1)$ & 0.162 \\
\hline \multicolumn{5}{|l|}{ Gender } \\
\hline Female & $48(87.3 \%)$ & $7(12.7 \%)$ & $3.8(0.6-25)$ & 0.167 \\
\hline Male & $26(96.3 \%)$ & $1(3.7 \%)$ & & \\
\hline \multicolumn{5}{|l|}{ Smoking } \\
\hline No & $54(90 \%)$ & $6(10 \%)$ & $0.9(0.24-3.4)$ & 0.877 \\
\hline Yes $^{\dagger}$ & $20(90.9 \%)$ & $2(9.1 \%)$ & & \\
\hline \multicolumn{5}{|c|}{ Miniscrews number per patient ${ }^{e}$} \\
\hline 1 & $6(100 \%)$ & 0 & $0.33(0.2-0.56)$ & $<0.001^{* * *}$ \\
\hline 2 & $36(100 \%)$ & 0 & & \\
\hline 3 & $2(66.7 \%)$ & $1(33.3 \%)$ & & \\
\hline 4 & $26(81.2 \%)$ & $6(18.8 \%)$ & & \\
\hline 5 & $4(80 \%)$ & $1(20 \%)$ & & \\
\hline \multicolumn{5}{|l|}{ Miniscrew length } \\
\hline $8 \mathrm{~mm}$ & $63(94 \%)$ & $4(6 \%)$ & $5.7(1.7-19.6)$ & $0.006 * *$ \\
\hline $10 \mathrm{~mm}^{\dagger}$ & $11(73.3 \%)$ & $4(26.7 \%)$ & & \\
\hline \multicolumn{5}{|l|}{ Miniscrew diameter } \\
\hline $1.2 \mathrm{~mm}$ & $57(95 \%)$ & $3(5 \%)$ & $5.6(1.4-21.8)$ & $0.013^{*}$ \\
\hline $1.4 \mathrm{~mm}^{\dagger}$ & $17(77.3 \%)$ & $5(22.7 \%)$ & & \\
\hline \multicolumn{5}{|l|}{ Malocclusion type } \\
\hline Angle I & $54(90 \%)$ & $6(10 \%)$ & $0.9(0.25-3.3)$ & 0.873 \\
\hline Angle II/ $1^{\dagger}$ & $20(90.9 \%)$ & $2(9.1 \%)$ & & \\
\hline \multicolumn{5}{|l|}{ Dentoalveolar abnormality ${ }^{\mathrm{b}}$} \\
\hline Crowding & $53(88.3 \%)$ & $7(11.7 \%)$ & $1.1(0.2-5.8)$ & 0.927 \\
\hline Open bite ${ }^{f}$ & $7(87.5 \%)$ & $1(12.5 \%)$ & & \\
\hline \multicolumn{5}{|l|}{ Site placement ${ }^{\mathrm{c}, \mathrm{e}}$} \\
\hline Retromandibular triangle & $3(60 \%)$ & $2(40 \%)$ & $0.07(0.01-0.5)$ & $0.008 * *$ \\
\hline Palatal & $7(70 \%)$ & $3(30 \%)$ & $0.11(0.03-0.5)$ & $0.004 * *$ \\
\hline Buccal $^{\dagger}$ & $63(95.5 \%)$ & $3(4.5 \%)$ & & \\
\hline \multicolumn{5}{|c|}{ Maxillary/mandibular placement } \\
\hline Maxilla & $58(93.5 \%)$ & $4(6.5 \%)$ & $3.6(0.8-17)$ & 0.102 \\
\hline Mandible & $16(80 \%)$ & $4(20 \%)$ & & \\
\hline \multicolumn{5}{|l|}{ Surgical placement procedure } \\
\hline Flapless $^{d}$ & $70(92.1 \%)$ & $6(7.9 \%)$ & $5.8(1.2-28.8)$ & $0.031 *$ \\
\hline Flapped $^{\mathrm{d}, \mathrm{f}}$ & $4(66.7 \%)$ & $2(33.3 \%)$ & & \\
\hline \multicolumn{5}{|l|}{ Placement soft tissue type ${ }^{e}$} \\
\hline Attached gingiva & $73(92.4 \%)$ & $6(7.6 \%)$ & $24.3(5.1-115.5)$ & $<0.001^{* * *}$ \\
\hline Movable mucosa ${ }^{\dagger}$ & $1(33.3 \%)$ & $2(66.7 \%)$ & & \\
\hline \multicolumn{5}{|c|}{ Orthodontic force applied on miniscrew } \\
\hline Intrusion & $11(84.6)$ & $2(15.4)$ & $0.21(0.034-1.3)$ & 0.094 \\
\hline Protraction & $2(66.7 \%)$ & $1(33.3 \%)$ & $0.077(0.005-1.168)$ & 0.065 \\
\hline Uprighting & $9(75 \%)$ & $3(25 \%)$ & $0.12(0.024-0.55)$ & $0.007 * *$ \\
\hline Retraction ${ }^{f}$ & $52(96.3 \%)$ & $2(3.7 \%)$ & & \\
\hline
\end{tabular}

${ }^{\text {a }}$ Quantitative scale;

${ }^{b}$ Fourteen patients did not present crowding or open bite. Their miniscrew procedures were considered successful;

${ }^{c}$ At the mesial site of \#47, a miniscrew was placed with success and it was not included in the statistical analysis;

${ }^{\mathrm{d}}$ Hand screwdriver;

e Most significant factor/variable using Bonferroni correction ( $P<0.0042,12$ factors);

${ }^{\mathrm{f}}$ Referral category;

$* P<0.05$

$* * P<0.01$

$* * * P<0.001$. 

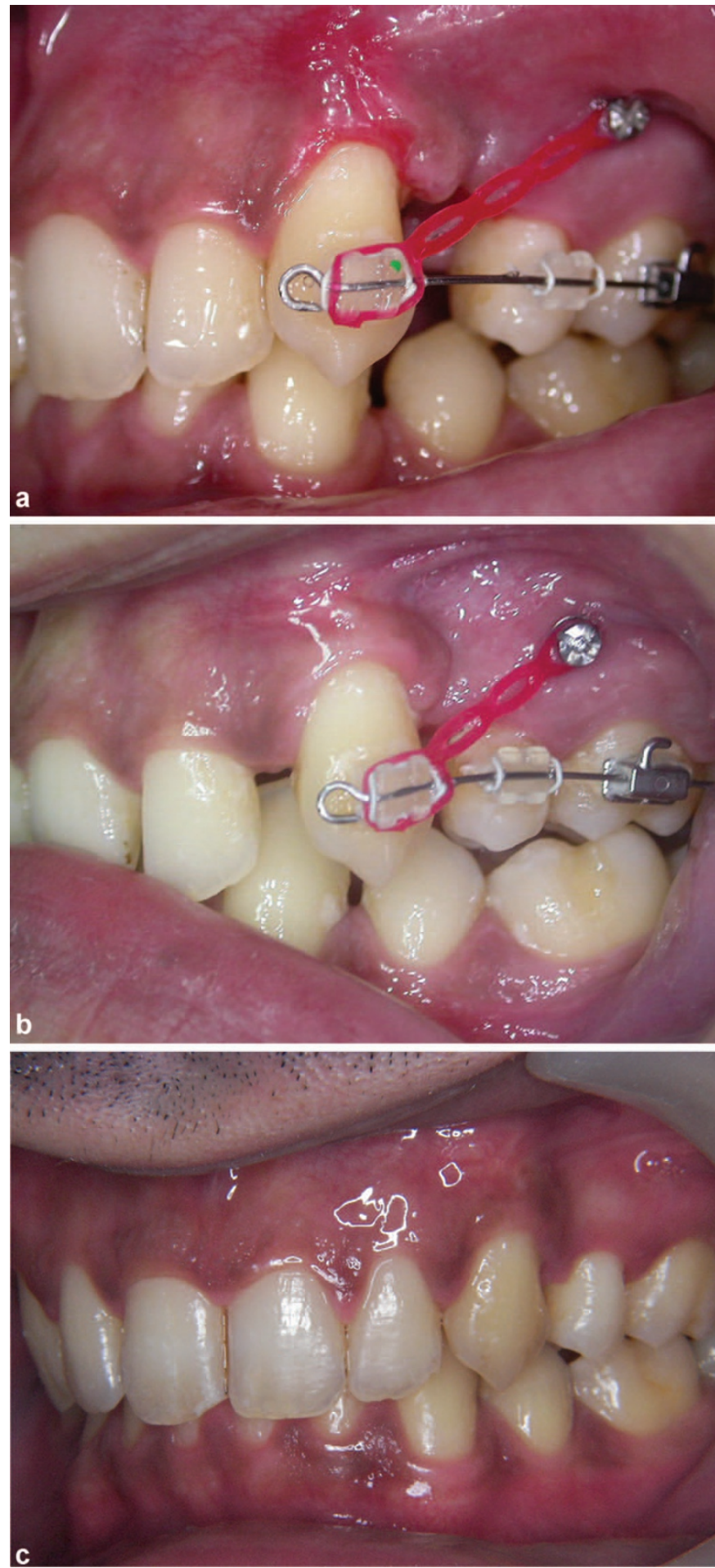

Figure 1 Upper canine retraction using a miniscrew, elastic force and sectional/segmented arch. Pre-treatment (a), during treatment (b) and posttreatment (c) photograph.

When the miniscrew length was $8 \mathrm{~mm}$, the probability of success was 5.7 times higher than when it was $10 \mathrm{~mm}$. Similarly, when the miniscrew diameter was $1.2 \mathrm{~mm}$, the probability of success was 5.6 times higher than when it was $1.4 \mathrm{~mm}$. All but eight of the miniscrews were inserted without a flap. The surgical placement procedure (flapped or flapless) significantly correlated with success rates.
Flapless placement resulted in a success rate per miniscrew that was 5.8 times greater than that of flap procedures. Last but not least, when a miniscrew was used for uprighting, the success rate was $88 \%$ lower when compared to that of miniscrews used for retraction (Figure 1).

According to the Bonferroni type I error correction method, the most statistically significant factors were: the number of miniscrews per patient, the site of miniscrew placement and the type of soft tissue within which the miniscrew was placed. As the number of miniscrews per patient increased, the success rate per miniscrew decreased significantly $(67 \%, P<0.001)$. Retromandibular triangle and palatal placement of miniscrews resulted in $93 \%(P=0.008)$ and $89 \%(P=0.004)$, respectively, lower success rates as compared to buccal placement. Furthermore, when a miniscrew was placed in the attached gingiva, there was a success rate that was 24 times greater than when it was placed in movable mucosa $(P<0.001)$.

The following factors showed no significant correlation with success rates: gender, patient age, smoking, maxillary/mandibular miniscrew placement, type of malocclusion and dentoalveolar abnormality (Table 3).

\section{DISCUSSION}

Miniscrews have been used for anchorage during orthodontic force application and various types of dental movement for a number of years. As early as 1983, a miniscrew was inserted by Creekmore and Eklund just below the anterior nasal spine so as to intrude the upper central incisors. ${ }^{17}$

The present study reported a success rate of $90.2 \%$ and probability of success was 9.3 times higher than probability of failure. Reports of success rates for miniscrews range from $0 \%{ }^{18}$ to $100 \% .{ }^{19-22}$ It should be noted that only one study has reported a success rate of a miniscrew type of $0 \% .{ }^{18}$ The vast majority of studies have reported success rates exceeding $80 \%{ }^{23-32}$ The range of success rates reported can be explained by the different success criteria applied in different studies and by the non-homogenous study samples in terms of various patient factors (age, gender, smoker/non-smoker, anatomic placement location, dentoalveolar abnormality, Angle Class, oral hygiene, etc.), miniscrew factors (type, diameter, length, etc.) and handling factors (surgical placement, force application, duration of loading, type of orthodontic movement, etc.). ${ }^{13-14,33}$

The most important finding of this study is that the number of miniscrews per patient was correlated with the miniscrew failure rate. For every additional miniscrew per patient, after the second one, the probability of success decreased by $67 \%$. This has not been demonstrated in previous studies. Chen et al. ${ }^{34}$ examined the number of miniscrews per patient as a variable, but they found no statistically significant difference. As far as we know, no other study has presented results showing that the number of miniscrews per patient is correlated with their success or failure rates, and, of course, this has to be confirmed by other studies before safe conclusions may be drawn. The cause for this finding is not easy to find, but one could attribute it to oral hygiene and the presence of inflammation. It is quite likely that the thoroughness of oral hygiene is increased when the number of miniscrews is limited and it is reduced in some of them when their number is increased in the same oral cavity. A clinical interpretation of this result might be that when a higher number of miniscrews are placed in the same patient, instructions and monitoring of their oral hygiene should be more intensive.

The type of soft tissue around miniscrews at the transmucosal site (attached gingiva or movable mucosa) presented significant correlation with success rates. When a miniscrew was placed in the attached 
gingiva, the success rate was 24 times higher than that in cases of movable mucosa placement. This is consistent with other researchers' results, who have reported that the type of soft tissue around miniscrews affects success rate. Two studies reported that the presence of non-keratinized mucosa resulted in higher failure rates. ${ }^{35-36}$ Similarly, Melsen and Verna ${ }^{37}$ and Mah and Bergstrand ${ }^{38}$ recommended that miniscrews should be inserted in keratinized gingiva. Conversely, Chaddad et al. ${ }^{24}$ found no correlation between success rate and placement in keratinized gingiva or non-keratinized mucosa. It has been suggested that when miniscrews are placed in keratinized gingiva, the probability of tissue hyperplasia and inflammation is lower, ${ }^{37,39}$ which makes it clear that miniscrews should be placed in keratinized gingiva. It seems that just like this type of gingiva is a very essential factor for periodontal health; similarly, the presence of keratinized gingiva around the miniscrews is important for the health of the surrounding tissues and, therefore, the stability and long-term maintenance without inflammation.

Tseng et al. ${ }^{31}$ found that the only statistically significant factor for miniscrew success rates was the placement site of miniscrews, particularly in the ramus. They reported a success rate of $100 \%$ when miniscrews were inserted in the region of the anterior upper and lower teeth, $95 \%$ when they were inserted in the buccal region of the posterior upper teeth, $85.7 \%$ when they were inserted in the buccal region of the posterior lower teeth and $60 \%$ when inserted in the mandibular ramus. Conversely, Miyawaki et al. ${ }^{18}$ found no statistically significant association of success rates with various placement sites. Similarly, another study has shown that the placement site (maxilla or mandible, left or right side, anterior or posterior to second premolar) presented no statistically significant association with success rates. ${ }^{40}$ Furthermore, another study has shown that maxillary or mandibular placement and placement that is anterior or posterior to second premolar were associated with success rates. ${ }^{34}$ According to another study, mandibular placement, as well as placement in the right mandibular or maxillary side showed statistical significance with higher failure rates. ${ }^{30}$ Miniscrews were lost from seven regions in this study: buccally between the roots of 25 and 26, buccally between the roots of 45 and 46 , buccally between the roots of 43 and 44 , palatally between the roots of 26 and 27, palatally between the roots of 16 and 17, palatally and mesially of 26 , and in the retromandibular triangle. When miniscrew placement sites were classified in terms of retromandibular triangle, palatal or buccal placement, a statistically significant correlation with success rates was found. Retromandibular triangle and palatal placement of miniscrews resulted in lower success rates as compared to buccal placement, whereas, in other studies, no significant differences in failure rates of miniscrews were reported, whether they were placed on the buccal or the lingual side. ${ }^{34,40}$ On the other hand, when classifying miniscrews in terms of maxillary or mandibular placement, there was no statistically significant correlation with success rates. Similar success rates for placement in the maxilla and the mandible have been reported, ${ }^{18,23-24,41-42}$ while higher success rates for placement in the maxilla have also been reported. ${ }^{27,30,43}$ It seems that the results, as far as the placement site of miniscrews is concerned, are not similar in the literature. From the above and the present study, it cannot be definitely concluded which site is superior for miniscrew placement.

The results presented here showed significant correlation of success rates with miniscrew length. When the miniscrew length was $8 \mathrm{~mm}$, the probability of success was 5.7 times higher than that of $10 \mathrm{~mm}$ long miniscrews. Chen et al. ${ }^{29}$ found that increased miniscrew length had a statistically significant effect on success rates, but, on the contrary,
Justen and de Bruyn ${ }^{44}$ found that miniscrew length had no influence. Tseng et al. ${ }^{31}$ found an overall success rate of $91.1 \%$ for miniscrews and $100 \%$ for miniscrews equal or longer than $12 \mathrm{~mm}$. They reported that the success rate increased with the length of the miniscrew, but the difference was not statistically significant. Furthermore, they claimed that the depth of miniscrew placement relative to its length and the location of placement were more critical and a minimum placement depth of $6 \mathrm{~mm}$ was recommended. A short miniscrew placed in a position with thick soft tissue, like the palatal mucosa, can easily become dislodged, ${ }^{31,45}$ so longer miniscrews are recommended for such sites. ${ }^{46}$ Of course, longer miniscrews have higher risks for injury to teeth roots or other anatomical features. Deguchi et al. ${ }^{47}$ recommended a length of around 6-8 $\mathrm{mm}$ for safe placement. In the present study, miniscrew diameter was found to have statistically significant correlation with success rates. The probability of success was 5.6 times higher when the miniscrew diameter was $1.2 \mathrm{~mm}$ than when it was $1.4 \mathrm{~mm}$, but according to another study, the diameter did not influence the outcome. ${ }^{44}$ Miyawaki et al. ${ }^{18}$ reported that miniscrews of a diameter of $1.0 \mathrm{~mm}$ or less were associated with mobility and failure. Similar results have been reported by other researchers, but for minimal increase in miniscrew diameter, and these authors recommended that miniscrews smaller than $1.3 \mathrm{~mm}$ in diameter should be avoided. ${ }^{48-49}$ This is consistent with a systematic review from 2009, which showed that miniscrews with a diameter exceeding or equal to $2 \mathrm{~mm}$ were 1.8 times less likely to fail than those with a diameter below $1.2 \mathrm{~mm} .{ }^{14}$ In this study, the greater probability of failure for miniscrews with a longer diameter and length, as compared to miniscrews with a shorter diameter and length, is probably due to the fact that the miniscrew failure probability was affected by the placement site. For example, in cases of palatal placement, where the failure rate was higher than that of buccal placement, the miniscrews inserted were of longer diameter and length.

In this study, it was observed that uprighting showed an $88 \%$ lower success rate as compared to retraction. No statistically significant difference in success rates was observed between retraction and intrusion or between retraction and protraction. Kuroda et al. ${ }^{28}$ studied the effect of orthodontic force applied to miniscrews on procedure success rates. They concluded that miniscrews $(1.3 \mathrm{~mm}$ in diameter; $6,7,8,10$ or $12 \mathrm{~mm}$ long) showed lower success rates for intrusion than retraction or protraction. The difference for retraction was statistically significant. Chen et al. ${ }^{40}$ reported that the risk of failure for self-drilling miniscrews was five times higher when they were used for tooth uprighting than for intrusion. Furthermore, Chen et al. ${ }^{34}$ noted that the success rate was lower when miniscrews were used for retraction or protraction as compared to those used for intrusion. It is possible for orthodontic forces with different directions to be applied on miniscrews, depending on the orthodontic movement desired. Higher success rates have been observed for retraction in some studies and for intrusion or protraction in others. It may be assumed that characteristics related to orthodontic movement, such as movement type, force applied, force direction and angle or type of mechanism between miniscrew and tooth, affect the success rate of miniscrews.

The surgical procedure for miniscrew placement (flapped or flapless) was also significantly correlated with success rate. Raising a flap decreases the success rate of miniscrew procedures. Miyawaki et al. ${ }^{18}$ found no correlation between surgical procedure (flapped or flapless) and success rate, but the opposite was reported by Kuroda et al., ${ }^{28}$ who presented a higher success rate for flapless procedures, while Hermann et al. ${ }^{50}$ showed lower success rates with flapless procedures. A possible 
reason leading to our result might be that the flap procedure for miniscrews placement was used in regions with movable mucosa. This view is also confirmed by other authors. ${ }^{37,39}$

Patients' Angle Class did not significantly correlate with success or failure rates in this study, and this is consistent with results from two other studies. ${ }^{35,40}$ Similarly, the patients' dentoalveolar abnormality (crowding or spacing) did not significantly correlate with the success rate of miniscrew procedures. Similarly, Miyawaki et al. ${ }^{18}$ also found that the presence or absence of crowding was not associated with success rates. It seems, therefore, that the success of miniscrews is not affected by dentoalveolar abnormality and/or maloclussion type.

Patient age did not seem to correlate with the success rate of miniscrews. Miyawaki et al. ${ }^{18}$ found lower success rates for patients under the age of 20 years $(80 \%)$ as compared to patients over 20 years $(85 \%-$ $88 \%)$, but these results were not statistically significant. Chen et al. found that younger patients faced a greater risk of failure. ${ }^{34}$ Similarly, Park et al. ${ }^{51}$ placed miniscrews in 13 patients and reported that failures were observed only in three patients of the under-14 age-group, while no failures were recorded in the 14-28 age group. Furthermore, Motoyoshi et al. ${ }^{41}$ found a significantly higher rate of success in adult patients than in adolescents. Conversely, Park ${ }^{52}$ observed that patients over the age of 20 years presented lower success rates than those below 20 years of age. Meanwhile, other authors have reported that a patient's age showed no statistically significant difference regarding the success or failure of miniscrews. ${ }^{30,35}$ It seems that the results of most studies agree that the younger age group presents lower success rates. It is suggested that the difference might be due to the higher metabolic rate of adolescents ( $\leqslant 20$ years old) as compared to that of adults, a fact that might affect success rates. ${ }^{52}$ This difference may also be associated with patients' oral hygiene. It is possible that, as the age of patients increases, much better oral hygiene is achieved because they become more conscientious, have a more mature attitude and look after their teeth more meticulously.

The variables of gender and smoking were not found to correlate with success rates, according to the results of this study and this has been postulated by other authors as well. ${ }^{23,30,32,42}$ There seems to be an agreement as far as the gender factor is concerned between this and other studies. Finally, it is proposed that placing miniscrews in smokers should be avoided and, when this is done, patients should be monitored very carefully. ${ }^{13}$

The average miniscrew loading time in the present study was 9 months, ranging from 1 to 14 months. The success rate was reduced by $47 \%$ for every additional month of loading. Similar findings were presented by Wiechmann et al., ${ }^{27}$ who estimated that the highest failure rate occurred during the first 100-150 days following loading. Furthermore, Moon et al. ${ }^{23}$ reported that most miniscrew losses were observed in the first 4 months after placement. From the results of the present study, in which all miniscrew failures took place within the first 4 months after placement, as well as from the studies referred to above, it seems that the first months of miniscrew loading, particularly the first 4 months, have a significant effect on success rate.

\section{CONCLUSIONS}

The success rate of miniscrews in this study was $90.2 \%$. The success rate per miniscrew decreased significantly as the number of miniscrews used per patient increased. Retromandibular triangle and palatal placement of miniscrews resulted in lower success rates as compared to buccal placement. Miniscrew placement in attached gingiva showed higher success rates than placement in movable mucosa. Furthermore, the variables of miniscrew length, miniscrew diameter, surgical placement procedure (flapped or flapless) and orthodontic force applied on the miniscrew presented significant correlation with success rates.

\section{ACKNOWLEDGEMENTS}

We wish to thank Karayiannis Vasilios, statistician, for his assistance with the statistical analysis.

1 Leonhardt A, Grondahl K, Bergstrom C et al. Long-term follow-up of osseointegrated titanium implants using clinical, radiographic and microbiological parameters. Clin Oral Implants Res 2002; 13(2): 127-132.

2 Weber HP, Crohin CC, Fiorellini JP. A 5-year prospective clinical and radiographic study of non-submerged dental implants. Clin Oral Implants Res 2000; 11(2): 144 153.

3 Buser D, Mericske-Stern R, Beranrd JP et al. Long-term evaluation of nonsubmerged ITI implants. Part I: 8-year life table analysis of a prospective multicenter study with 2359 implants. Clin Oral Implants Res 1997; 8(3): 161-172.

4 Lekholm U, van Steenberghe D, Herrmann I et al. Osseointegrated implants in the treatment of partially edentulous jaws: a prospective 5-year multicenter study. Int J Oral Maxillofac Implants 1994; 9(6): 627-635.

5 Adell R, Eriksson B, Lekholm U et al. A long-term follow-up study of osseointegrated implants in the treatment of totally edentulous jaws. Int J Oral Maxillofac Implants 1990; 5(4): 347-359.

6 Higuchi KW, Slack JM. The use of titanium fixtures for intraoral anchorage to facilitate orthodontic tooth movement. Int J Oral Maxillofac Implants 1991; 6(3): 338-344.

7 Stean $\mathrm{H}$. Clinical case report: an improved technique for using dental implants as orthodontic anchorage. J Oral Implantol 1993; 19(4): 336-340.

8 Wehrbein H, Feifel H, Diedrich P. Palatal implant anchorage reinforcement of posterior teeth: prospective study. Am J Orthod Dentofacial Orthop 1999; 116(6): 678-686.

9 Wehrbein H, Merz BR, Diedrich P et al. The use of palatal implants for orthodontic anchorage. Design and clinical application of the orthosystem. Clin Oral Implants Res 1996; 7(4): 410-416.

10 Costa A, Raffainl M, Melsen B. Miniscrews as orthodontic anchorage: a preliminary report. Int J Adult Orthodon Orthognath Surg 1998; 13(3): 201-209.

11 Block MS, Hoffman DR. A new device for absolute anchorage for orthodontics. Am J Orthod Dentofacial Orthop 1995; 107(3): 251-258.

12 Kanomi R. Miniscrew for orthodontic anchorage. J Clin Orthod 1997; 31(11): 763767

13 Reynders R, Ronchi L, Bipat S. Miniscrews in orthodontics: a systematic review of the literature. Am J Orthod Dentofacial Orthop 2009; 135: 564.e1-564.e19.

14 Schätzle M, Männchen R, Zwahlen M et al. Survival and failure rates of orthodontic temporary anchorage devices: a systematic review. Clin Oral Implants Res 2009, 20(12): 1351-1359.

15 Zeger SL, Liang KY. Longitudinal data analysis for discrete and continuous outcomes. Biometrics 1986; 42(1): 121-130.

16 Liang KY, Zeger SL. Longitudinal data analysis using generalized linear models. Biometrics 1986; 73(1): 13-22.

17 Creekmore TD, Eklund MK. The possibility of skeletal anchorage. J Clin Orthod 1983; 17(4): 266-269.

18 Miyawaki S, Koyama I, Inoue M et al. Factors associated with the stability of titanium screws placed in the posterior region for orthodontic anchorage. Am J Orthod Dentofacial Orthop 2003; 124(4): 373-378.

19 Kinzinger G, Gulden N, Yildizhan F et al. Anchorage efficacy of palatally-inserted miniscrews in molar distalization with a periodontally/miniscrew-anchored distal jet. J Orofac Orthop 2008; 69(2): 110-120.

20 Thiruvenkatachari B, Pavithranand A, Rajasigamani K et al. Comparison and measurement of the amount of anchorage loss of the molars with and without the use of implant anchorage during canine retraction. Am J Orthod Dentofacial Orthop 2006; 129(4): 551-554.

21 Liou EJ, Pai BC, Lin JC. Do miniscrews remain stationary under orthodontic forces? Am J Orthod Dentofacial Orthop 2004; 126(1): 42-47.

22 Gelgor IE, Buyukyilmaz T, Karaman Al et al. Intraosseous screw-supported upper molar distalization. Angle Orthod 2004; 74(6): 838-850.

23 Moon CH, Lee DG, Lee HS et al. Factors associated with the success rate of orthodontic miniscrews placed in the upper and lower posterior buccal region. Angle Orthod 2008; 78(1): 101-106.

24 Chaddad K, Ferreira AH, Geurs N et al. Influence of surface characteristics on survival rates of miniscrews. Angle Orthod 2008; 78(1): 107-113.

25 Luzi C, Verna C, Melsen B. A prospective clinical investigation of the failure rate of immediately loaded miniscrews used for orthodontic anchorage. Prog Orthod 2007 8(1): 192-201.

26 Hedayati Z, Hashemi SM, Zamiri B et al. Anchorage value of surgical titanium screws in orthodontic tooth movement. Int J Oral Maxillofac Surg 2007; 36(7): 588-592.

27 Wiechmann D, Meyer U, Büchter A. Success rate of mini- and micro-implants used for orthodontic anchorage: a prospective clinical study. Clin Oral Implants Res 2007; 18(2): 263-267 
28 Kuroda S, Sugawara Y, Deguchi T et al. Clinical use of miniscrew implants as orthodontic anchorage: success rates and postoperative discomfort. Am J Orthod Dentofacial Orthop 2007; 131(1): 9-15.

29 Chen $\mathrm{CH}$, Chang $\mathrm{CS}$, Hsieh $\mathrm{CH}$ et al. The use of microimplants in orthodontic anchorage. J Oral Maxillofac Surg 2006; 64(8): 1209-1213.

30 Park HS, Jeong SH, Kwon OW. Factors affecting the clinical success of screw implants used as orthodontic anchorage. Am J Orthod Dentofacial Orthop 2006; 130(1): 1825.

31 Tseng $\mathrm{YC}$, Hsieh $\mathrm{CH}$, Chen $\mathrm{CH}$ et al. The application of miniscrews for orthodontic anchorage. Int J Oral Maxillofac Surg 2006; 35(8): 704-707.

32 Motoyoshi M, Hirabayashi M, Uemura $\mathrm{M}$ et al. Recommended placement torque when tightening an orthodontic miniimplant. Clin Oral Implants Res 2006; 17(1): 109-114.

33 Chen Y, Kyung HM, Zhao WT et al. Critical factors for the success of orthodontic miniscrews: a systematic review. Am J Orthod Dentofacial Orthop 2009; 135(3): 284-291.

34 Chen $\mathrm{YJ}$, Chang $\mathrm{HH}$, Huang $\mathrm{CY}$ et al. A retrospective analysis of the failure rate of three different orthodontic skeletal anchorage systems. Clin Oral Impl Res 2007; 18(6): 768-775.

35 Viwattanatipa N, Thanakitcharu S, Uttraravichien A et al. Survival analyses of surgical miniscrews as orthodontic anchorage. Am J Orthod Dentofacial Orthop 2009; 136(1): 29-36.

36 Cheng SJ, Tseng IY, Lee JJ et al. A prospective study of the risk factors associated with failure of miniscrews used for orthodontic anchorage. Int J Oral Maxillofac Implants 2004; 19(1): 100-106.

37 Melsen B, Verna C. Miniscrew implants: the Aarhus anchorage system. Semin Orthod 2005; 11(1): 24-31.

38 Mah J, Bergstrand F. Temporary anchorage devices: a status report. J Clin Orthod 2005; 39(3): 132-136

39 Maino BG, Mura P, Bednar J. Miniscrew implants: the spider screw anchorage system. Semin Orthod 2005; 11: 40-46.

40 Chen YJ, Chang HH, Lin HY et al. Stability of miniplates and miniscrews used for orthodontic anchorage: experience with 492 temporary anchorage devices. Clin Oral Imp/ Res 2008; 19(11): 1188-1196.

41 Motoyoshi M, Matsuoka M, Shimizu N. Application of orthodontic miniscrews in adolescents. Int J Oral Maxillofac Surg 2007; 36(8): 695-699.
42 Motoyoshi M, Yoshida T, Ono A et al. Effect of cortical bone thickness and implant placement torque on stability of orthodontic miniscrews. Int J Oral Maxillofac Implants 2007; 22(5): 779-784.

43 Kuroda S, Yamada K, Deguchi T et al. Root proximity is a major factor for screw failure in orthodontic anchorage. Am J Orthod Dentofacial Orthop 2007; 131(4 Suppl): 6873.

44 Justens E, de Bruyn H. Clinical outcome of miniscrews used as orthodontic anchorage. Clin Implant Dent Relat Res 2008; 10(3): 174-180.

45 Hong RK, Heo JM, Ha YK. Lever-arm and mini-implant system for anterior torque control during retraction in lingual orthodontic treatment. Angle Orthod 2005; 75(1): 129-141.

46 Berens A, Wiechmann D, Dempf R. Mini- and micro-screws for temporary skeletal anchorage in orthodontic therapy. J Orofac Orthop 2006; 67(6): 450-458.

47 Deguchi T, Nasu M, Murakami K et al. Quantitative evaluation of cortical bone thickness with computed tomographic scanning for orthodontic implants. Am J Orthod Dentofac Orthop 2006; 129(6): 721.e7-721.e12.

48 Carano A, Melsen B. Implants in orthodontics. Interview. Prog Orthod 2005; 6(1): 6269

49 Carano A, Lonardo P, Velo $\mathrm{S}$ et al. Mechanical properties of three different commercially available miniscrews for skeletal anchorage. Prog Orthod 2005; 6(1): 82-97.

50 Herman RJ, Currier GF, Miyake A. Miniscrew anchorage for maxillary canine retraction: A pilot study. Am J Orthod Dentofacial Orthop 2006; 130(2): 228235.

51 Park HS, Lee SK, Kwon OW. Group distal movement of teeth using microscrew implant anchorage. Angle Orthod 2005; 75(4): 602-609.

52 Park HS. Clinical study on success rate of microscrew implants for orthodontic anchorage. Korean J Orthod 2003; 33(3): 151-156.

(c) This work is licensed under a Creative Commons Attribution-NonCommercial-NoDerivative Works 3.0 Unported License. To view a copy of this license, visit http:// creativecommons.org/licenses/by-nc-nd/3.0 